\title{
Differences between China and Japan from the Changes of Foreign Policy at the End of the Shogunate Era
}

\author{
Mei Han \\ School of Foreign Languages, East China University of Science and Technology, Shanghai, China \\ Email: Akari0425@163.com
}

How to cite this paper: Han, M. (2021) Differences between China and Japan from the Changes of Foreign Policy at the End of the Shogunate Era. Open Access Library Journal, 8: e7874.

https://doi.org/10.4236/oalib.1107874

Received: August 20, 2021

Accepted: September 4, 2021

Published: September 7, 2021

Copyright $\odot 2021$ by author(s) and Open Access Library Inc.

This work is licensed under the Creative Commons Attribution International License (CC BY 4.0).

http://creativecommons.org/licenses/by/4.0/

\section{(c) (i) Open Access}

\begin{abstract}
In the 17th century, European countries gradually ushered in the dawn of modern enlightenment. Western countries desperately developed navigation and foreign trade and carried out colonial expansion. However, at this time, the feudal rulers of China and Japan in East Asia secluded the country from the outside world. As a result, it has brought serious obstacles to the development of politics, economy and culture. With the arrival of Western powers, China and Japan showed different attitudes towards the forced founding of the country.
\end{abstract}

\section{Subject Areas \\ History, Society}

\section{Keywords}

Foreign Policy, China, Japan, Shogunate Era

\section{1. 日本闭关锁国的背景及其内容}

幕府的对外政策从第二代将军德川秀忠时起, 开始向锁国政策转变。1616 年, 规定欧洲船只只能在平户、长崎两港停泊交易, 1624 年, 拒绝与西班牙 通商。 30 年代后, 加快锁国步伐, 连续 5 次发布锁国令。1 1633 年发布第 1 次 锁国令。禁止奉书船以外船只渡航。此外, 禁止滞留外国 5 年以上的日本人 回国。1634 年第 2 次锁国令, 再次通达第 1 次锁国令的内容。1635 年第 3 次 锁国令, 宣布中国(明朝)、荷兰以外的船只只能进入长崎, 禁止所有在外的 日本人回国。1636 年第 4 次锁国令, 将与贸易没有关系葡萄牙人妻子(包括日 本混血儿)总共放逐了 287 人到澳门, 其余滞留在长崎出岛。1 637 年岛原之乱 
之后, 1639 年发布第 5 次锁国令, 禁止葡萄牙船只入港。

直到 1854 年美国海军军官佩里率舰吒关为止。日本的锁国是在禁教过程 中完成的。日本的政权结构是幕藩体制, 即由德川家康建立、由幕府和藩国 共同统治的封建制度, 其中, 征夷大将军是政权的实际控制者, 天皇和朝廷 则被征夷大将军和幕府架空权力。此外地方藩、特别是外藩拥有相对的地方 割据之权。幕府建立初期, 地方藩大名拥有对外贸易的权力, 这并不是幕府 对大名的支持, 而是江户时代之前的室町时代就留下的传统。随着大名在从 事对外贸易中财富的不断积累和势力的扩大，幕府中央政权的危机感日增。 为此, 幕府政府通过禁止基督教、颁发对外贸易的特许证, 来制止大名的对 外贸易和传教的西班牙、葡萄牙商人来日, 以加强对对外贸易的控制。

随着锁国体制的完成, 幕府政府将大名的对外贸易权集中到自己手中, 基本上制止了大名利用对外贸易扩大割据势力的危险, 也将与大名关系密切 的西班牙人和葡萄牙人驱逐出日本, 从而巩固了幕府的中央权力。禁教的目 的是为了垄断对外贸易权, 削弱地方大名的实力, 加强幕府中央政权的权威 [1]。锁国时代, 德川幕府虽然禁止外国人来日本贸易, 只开放长崎一港允许 荷兰和中国商船进行有限的贸易。另外, 在长崎一港通商外, 在当时还有对 马藩的朝鲜贸易和萨摩藩的琉球贸易。锁国期间, 日本幕府垄断内外信息交 流渠道, 禁止平民百姓打探情报, 但自身却十分关注海外信息。幕府向荷兰 东印度公司和唐船打探情报, 并将其提供的情况编为《荷兰风说书》和《唐 人风说书》[2]。

\section{2. 中国闭关锁国的背景及其内容}

就在日本开始实行锁国之时, 中国发生了改朝换代。1644 年, 清军从东 北入关, 攻占北京, 建立了清王朝, 取代明朝的统治。清初, 曾实行 “海禁 政策”, 严令 “片板不准下海”。1646 年清朝在公布《大清律集解附律》时 即保留了其蓝本 《大明律》中有关 “私出外境及违禁下海” 的条文, 自此清 朝开始实行 “海禁” , 直到 1684 年在全国正式开放 “海禁” 为止, 本国商民 的出海贸易(除采办洋铜的官本商船外)以及外国商船的来华贸易基本上受到 禁止。

马克思曾经深刻地指出: “推动这个新的王朝(指清王朝)实行这种政策 的更主要的原因, 是它害怕外国人会支持很多的中国人在中国被鞑靼人(指满 族)征服以后大约最初半个世纪里所怀抱的不满情绪。” [3]清王朝的海禁政策 一度正是为了镇压以台湾为基地的郑成功反清势力。清政府主要担心国内的 反对势力与外国人联合, 来威胁它的统治。锁国的目的就是为了割断这种联 系, 以维护其统治。起初的防范重点是在国内, 强迫沿海居民内迁, 不准出 海。后期的防范重点转到防范和限制外国人来华。不过, 在清初 “海禁” 期 间, 海外国家却可以凭借清朝允许的 “朝贡” 活动前来中国贸易。1684 年, 清朝在东南沿海地区正式设立了粤、闽、浙、江四海关, 从此开放了本国商 民的出海贸易和外国商船的来华贸易。1 757 年, 又关闭了江苏云台山、浙江 宁波、福建漳州三处对外开放的海港, 只留下广东省的广州一口与外国贸易, 并对外商的行动和进出口货物加以种种限制, 制订了一套愈加具体的闭关政 
策, 即清朝把外国商人的来华贸易从原来的四个海关所属港口自由选择改为 只许广州一口通。本国商民的出海贸易, 在 1835 年左右因为 “防夷” 的需要 而被清朝政府禁止[4]。

中日闭关锁国的相同点与不同点如表 1 所示。

\section{表 1. 中日闭关锁国对比}

\begin{tabular}{|c|c|c|c|}
\hline & & 中国闭关锁国 & 日本闭关锁国 \\
\hline 相同点 & \multicolumn{3}{|c|}{ 为了维护中央统治权力, 防止国内势力与外国人联合 } \\
\hline \multirow[t]{5}{*}{ 不同点 } & 时间 & $1646 \sim 1840$ 年 & $1616 \sim 1854$ 年 \\
\hline & \multirow{4}{*}{ 具体政策 } & $\begin{array}{l}\text { 只开放长崎允许荷兰和 } \\
\text { 中国商船进行有限贸易 }\end{array}$ & $\begin{array}{c}\text { 清初实行“海禁”政策 } \\
\text { 保留朝贡贸易 }\end{array}$ \\
\hline & & $\begin{array}{l}\text { 对马藩(朝鲜贸易) } \\
\text { 萨摩藩(琉球贸易) }\end{array}$ & $\begin{array}{c}1684 \text { 年在东南沿海地区开放粤、闽、 } \\
\text { 浙、江四海关 }\end{array}$ \\
\hline & & $\begin{array}{c}\text { 打探海外信息: } \\
\text { 荷兰东印度公司《荷兰风说书》 } \\
\text { 唐船《唐人风说书》 }\end{array}$ & 1757 年只留广州一口与外国贸易 \\
\hline & & & 1835 年禁止本国商民出海贸易 \\
\hline
\end{tabular}

\section{3. 中日被迫开国对比及其举措}

1840 年 5 月 29 日, 英国军舰封锁广州珠江口, 第一次鸦片战争正式爆发, 中国被迫打开国门。尽管有林则徐、关天培、陈化成等爱国将领的浴血奋战 和沿海人民的自发抵抗。但是, 清朝最高统治集团昏庸腐败, 政治反动, 指 挥混乱, 武器落后, 思想愚昧, 最终导致了中国在这场战争中的失败。1842 年 8 月, 在南京城下签订了近代第一个丧权辱国的不平等条约《中英南京条 约》。除了割让香港和赔款外, 正式开放了东南沿海的广州、厦门、福州、 宁波、上海等五个通商口岸。接着又与英国、美国、法国等国签订了《中英 虎门条约》、《中美望厦条约》、《中法黄埔条约》等一批不平等条约。西 方列强又算取了协定关税、领事裁判权、最惠国待遇等特权。中国从此开始 沦入半殖民地的深渊, 标志着中国近代史的开端。

受到鸦片战争的震动和刺激, 中国地主阶级知识分子中间一批爱国开明 的有识之上, 开始睁开眼睛看世界, 了解国际形势, 研究外国史地, 总结鸦 片战争失败的教训, 寻找救国的道路和抵御外敌的方法。他们认为这些是 “凡 有血气者所宜愤悱，凡有耳目心知者所宜讲画者” [5]。鸦片战争及战后闭关 大门的开放, 也使他们获得了一些了解西洋知识的途径。这对近代中国人接 受西学起了一定的作用, 可是在中国强大的保守势力和传统文化的抵制下, 收效不大, 也因此没有受到清朝统治集团应有的重视和采纳。

中国和日本的闭关锁国状态都是被工业革命后的西方资本主义国家打破 的。以首次订立开放门户条约的时间而言, 中国先于日本 12 年, 但在被迫开 放门户以后, 日本开国的力度和主动性明显高于中国。首先, 日本对于政治 体制变革更加积极彻底。1 868 年明治维新, 日本结束长达六百多年的武士封 建制度，建立新式政府，废除江户时期的等级制度，并且采取一系列版籍奉 
还、废番置县的政策, 在政治、经济、文化教育等全面推进。而中国政府虽 开展洋务运动, 主张 “中学为体, 西学为用” , 学习西方先进技术, 但并未 涉及到体制变革, 而且由于朝廷保守派的反对, 极大阻挠了洋务运动的发展, 最终导致失败。其次, 两国对于海外信息的接纳程度不同。日本政府虽闭关 锁国, 限制港口对外贸易, 但是仍然保持打探海外消息, 而清政府自视天朝 大国, 忽视了海外情况。最后, 两国对于新型人才的重视程度不同, 明治维 新之后, 日本派出岩仓使节团考察西方文化国情, 引进新的组织和思维方式, 并且回国后, 使节团成员担任主要领导角色, 力图将日本改造为现代国家。 清政府也曾派出使节团, 1868 年向海外派遣了中国近代第一个正式外交使团, 即蒲安臣使节团, 历时两年八个月, 先后访问了欧美 11 个国家, 但是其影响 仅仅处于了解外情, 回国后, 由于保守派的反对和阻挠, 使节团中的新型人 才所提出的举措并未得到落实。

与中国人对撞开广州门户的英国人充满愤慨相反, 日本人对于 1853 年佩 里吒关并没有抱有憎恨, 甚至有些人持有正面肯定的态度。中国战败的消息 传到日本, 让幕府开始重新考虑此前的锁国政策, 他们担心采取过激行动会 引起冲突, 于是在 1842 年修改驱逐令, 指示各藩可以允许外国船只在日本少 数港口加煤加水。西方国家并不满足于日本这种微小的让步, 美国更希望率 先吒开日本的国门来获取利益。1803 年美国就派船到长崎, 请求通商, 遭到 拒绝。1 837 年, 美国又以送还遭遇海难的日本漂流民为由, 派 “莫里森” 号 船驶往日本的浦贺、鹿儿岛, 遭到炮击。这一事件使美国政府考虑用武力来 迫使日本打开国门。1 852 年美国派马修.佩里出任东印度舰队司令, 1853 年 7 月 14 日, 佩里率领士兵登陆日本, 并向天皇递交了美国总统要求日本开放的 亲笔信。由于开国所引起的日本社会的变动, 使得幕藩封建统治成为过时的 东西, 日本要在 19 世纪世界里作为一个民族国家自立下去, 就必须出现与近 代社会相适应的国家政权。于是, 无法经受内忧外患的幕府被倒幕派所推翻, 政权转向新生的明治政府。明治政府面对列强, 表现出虔诚地向西方学习的 决心, 很快朝野上下就逐渐从迷茫中走出来, 找到了共同目标, 即争取和维 护国家完整独立, 推行了 “文明开化”, “殖产兴业”, “富国强兵” 等近 代化变革, 这些举措都对日本近代化发展以及自身国力的增强有着紧密的联 系。

\section{4. 结语}

闭关与锁国是中日两国封建统治者采取的一种消极保守的对外政策, 它 人为地把本国自我封闭, 与世界隔绝开来。它阻碍了中日两国对外贸易和与 各国的经济文化交流, 堵塞了观察世界、学习各国先进科学技术的渠道, 禁 锢了两国人民的眼界和思想。以至在十七世纪至十九世纪中叶这二百多年间, 造成了东亚在经济、文化、科学技术发展上的停滞和落后, 而且与经过了资 产阶级革命、工业革命而飞跃发展的西方资本主义国家之间, 差距越拉越大。 然而, 在中日相继被迫开国之后, 中日两国所采取的应对差距和思想变化, 也决定了两国接下来的发展渐行渐远。 


\section{Conflicts of Interest}

The author declares no conflicts of interest.

\section{References}

[1] 贾秀梅, 郝士宏. 近代前中日两国锁国政策的比较研究[J]. 山西高等学校社会科 学报, 2007, 19(9): 128-131.

[2] 刘晓莉. 日本“锁国闭关”的再认识[J]. 咸宁师专学报, 2001, 21(1): 74-77.

[3] 马克思. 马克思恩格斯选集 [M]. 北京: 人民出版社, 1995: 453.

[4] 陈尚胜. 论清朝前期国际贸易政策中内外商待遇的不公平问题一一对清朝对外 政策具有排外性观点的质疑[J]. 文史哲, 2009(2): 101-111.

[5] 魏源. 海国图志 [M]. 长沙: 岳麓书社, 2011.

\section{Appendix (Abstract and Keywords in Chinese)}

\section{从幕末对外政策变化看中日差别}

摘要: 十七世纪, 欧洲各国逐渐迎来近代启蒙的曙光, 西方国家拼命发展航 海事业和对外贸易，进行殖民扩张。可是，东亚的中国与日本的封建统治者 却在这时紧闭起自己的国门，不约而同地实行 “闭关政策” 与 “锁国政策” 。 其结果，给本国政治、经济、文化的发展带来了严重的阻碍。随着西方列强 的到来, 中日两国面对被迫开国的局面又呈现了不同的态度。

关键词：对外政策，中日，幕末时期 